\title{
ADMINISTRAÇÃO DO TRABALHO
}

\author{
IDEOLOGIAS ENVOLVIDAS \\ $E$ \\ DEMOCRACIA NA EMPRESA
}

Isabel Lausanne Carneiro Mota

\section{INTRODUÇÃO}

Estas considerações sobre as relações de trabalho tentam revelar a necessidade de um esclarecimento conceitual sobre a questão da "participação": da participação ou da integração do trabalhador nos vários níveis da vida empresarial. Uma questão que tem sido uma constante nas propostas patronais e sindicais de mudança dos padrões de relacionamento social no mundo do trabalho.

Vista sobre outro prisma, a questão da participação tern colocado na ordem do dia a problemática da democracia empresarial. A gestão participativa aparece, então, ressuscitando propostas teóricas do século XVIII sobre o exercício e a importância da participação cotidiana do indivíduo, tanto na comunidade quanto no trabalho.

A partir destas observações, pretendemos esboçar uma pequena história da evolução da organização social da produção. Uma evolução composta por momentos de maior ou menor participação, de maior ou menor influência dos vários sujeitos do mundo do trabalho. Como marco inicial escolhemos a escola taylorista e os principais mo-

Economista. Mestranda em Economia, UFPB, Campus II. 
mcntos conceituais da gestão empresarial que lhe "sucederam"l : o fordismo, a gestão participativa, a co-gestão, o enriquecimento de cargos, as TRH (Técnicas de Recursos Humanos), as TOSP (Técnicas de Organização Social da Produção), as TAF (Técnicas de Automação Flexiveis), o Neo-Fordismo, dentre outros. Todos eles momentos especifico das formas de administração empresarial relacionadas às "teorias da modernização", cujo objetivo primeiro é o questionamento dos métodos de automação e a rigidez tecnológica.

Os vários padrões das relações de trabalho encontrados nestas formas organizacionais constituem uma categoria de análise importante, não apenas porque podem ressaltar ou mascarar as reais condições em que se processa o trabalho numa formação social determinada, mas também porque podem chamar a atenção, ou mesmo dissimular, as caractcrísticas das estruturas das relações sociais que as determinam.

As próprias mudanças de significado, assim como os deslocamento dos seus conteúdos conceituais, deixam-nos entrever a importância de se estudar as relações de trabalho através de suas manifestações históricas concretas. Enfim, nada podemos dizer sobre as relações de trabalho se não atentarmos para as caracteristicas conjunturais que, estas sim, especificam a noção genérica (e quase sempre vazia) de "Relações de Trabalho".

\section{SINTESE CRITICA DAS PRINCIPAIS FORMAS DE GERENNCIA CIENTIFICA}

A introdução da gerência científica nas últinnas décadas do século XIX, teve como mentor o então engenheiro Frederick Taylor: o criador do modelo de automação rígida do trabalho. A escola que levaria o seu nome, escola taylorista, introduziu a racionalização do trabalho operário através da análise de "Tempo e Movimento". Taylor desenvolveu estudos objetivos sobre a administração científica que fragili-

' Por vezes a concomitância, e não a sucessão, é a forma adequada de expressão das diversas escolas de gestão empresarial. 
zaram, substancialmente, a crença numa administração inspirada em critérios subjetivos.

A abordagem de Taylor parte do princípio (não-reversivo) que são as partes que constituem o todo e, por isso, ele define o operário como sendo um micro-sistema que deve moldar-se às exigências de um sistema maior, para que ele possa, então, dar o melhor de seu esforço e maximizar a produção num periodo dado de tempo.

Através do estudo de "tempos e movimentos", Taylor decompôs cada uma das etapas do trabalho e promoveu uma nova divisão. Com isso, ele visava eliminar movimentos inúteis e simplificar os movimentos que são necessários para o "melhor" desempenho do trabalhador na produção. Para desenvolver praticamente estas idéias, Taylor criou um tempo-padrão de execução. Neste tempo-padrão, cada uma das tarefas vinculadas ao trabalhador individual deve ser executada no menor tempo possivel. Esses são os fundamentos da racionalização do trabalho. Uma racionalização cujo objetivo principal e a diminuição dos desperdícios de tempo e o concomitante aumento dos rendimentos, tanto dos operários, quanto dos meios de produção.

$O$ estudo de tempos e movimentos permitiu que se forjasse uma nova divisão do trabalho e uma caracteristica especialização do operário. Essa divisão do trabalho (micro-sistêmica) tem como intuito aumentar a eficiência produtiva de acordo com as aptidões de cada indivíduo. $\mathrm{O}$ trabalho intelectual foi separado do braçal, de forma a condicionar cada trabalhador ao melhor exercício de sua especialização. Com essa especialização, desenvolveu-se o que hoje se conhece como "padronização do trabalho", ou seja, uma vez que o operário executa permanentemente apenas uma única operação, torna-se aí mais hábil e veloz.

Portanto, o taylorismo consiste em um controle direto da produção, onde os métodos de concepção são pensados previamente pela gerência, ajustando o trabalhador a uma cota de produção máxima diária rigidamente estabelecida.

A dinâmica taylorista consiste no controle pessoal dos operários, comparados quotidianamente com trabalhadores exemplares, 
com trabalhadores escolhidos "a dedo" pela gerência e que se tornam "os olhos do capital" no chão de empresa. A finalidade de utilizar estes trabalhadores "superdotados" é a de pressionar ideologicamente os outros individuos a tornarem-se mais eficientes e ocupar cargos de igual valia ou semelhantes.

Sinteticamente, então, o taylorismo se apresenta como a utilização ideológica do conhecimento científico aplicado. A utilização desta idcologia se realizando através da apropriação do que resta do saber do trabalhador, "transformando-o" em normas e métodos, desumanizando-o.

O primeiro efeito significativo do Taylorismo, que o coloca como doutrina-mãe da teoria da administração, é a eliminação do chamado "marca-passo sistemático". Uma vez que a divisão do trabalho está organizada para não permitir desperdícios de tempo, pode-se fixar mínimos de produção que pressionem o trabalhador no sentido de melhorar a cada dia o seu nivel de produtividade.

O segundo efeito é sobre as atividades de concepção. Esta foi arrancada do chão de fábrica e levada a ser pensada pela gerência. Esse sistema de separação entre concepção e execução, "era tão somente um meio para que a gerência efetuasse o controle do modo concreto de exercício de toda a atividade do trabalho, desde a mais simples até a mais complexa" ${ }^{2}$.

Esquematicamente a desarticulação entre execução e concepção é pensada da seguinte forma:

- racionalização do trabalho: aumento de eficiência;

- Sistema fechado: binômio homem-máquina;

- Incentivo a que os trabalhadores raciocinem sob a ótica da produção; produtividade como ganho salarial;

${ }^{2}$ BRAVERMAN, H. Trabalho e Capital Monopolista. São Paulo, Ed. Zahar, 1978, p. 41. 
- Divisão e hierarquização do trabalho: jugo do trabalho braçal pelo intelectual;

- Sistema formal: a organização cria regras e sistemas que deverão guiar a organização e os operários;

- Reunir os trabalhadores no seu próprio ambiente de produção: facilitar a fixação da idéia de responsabilidade pelo trabalho executado;

- Fixação da jornada de trabalho: cota de mínimos de produção que deverá ser cumprida pelo operário. Caso não haja o cumprimento destas normas, deve-se elastecer a jornada, porém sem remuneração equivalente;

- Execução de normas contra distrações, conversas no local de trabalho, abandono, etc.;

-Supervisão atenta dos trabalhadores;

Diante destes mandamentos, fixados aos trabalhadores como normas de "bem-viver" do homem em seu local de trabalho, e fora dele, Taylor analisou com muita perícia cada uma destas formas de desarticulação dos vários momentos do trabalho. Dado o seu tempo de convivência em várias alas da produção, nas quais atuou como operário, ele pode conhecer muito bem o propósito de determinadas displicência por parte dos trabalhadores. $\mathrm{O}$ jogo do marca-passo sistemático ${ }^{3}$ teve o seu fim com o controle explícito e implicito: a forma explícita, caracteriza-se por punições que gerariam uma diminuição de salário e, por outro lado, em trabalho extra sem remuneração. A forma implícita, por sua vez, faz parte do que Taylor chamava de "controle horas/produção", definido muitas vezes nos controles da própria máquina e, quando não, num jogo psicológico, chamado de um "ótimo-dia de trabalho", cuja

${ }^{3} \mathrm{O}$ jogo do marca-passo sistemático é conhecido entre os trabalhadores como a forma de passar o tempo de produção de maneira mais lenta: atrasando o tempo de serviço, fazendo com que as horas de produção passem sem o cumprimento de todas as tarefas. 
significação seria puramente fisiológica, exigindo do trabalhador todo o trabalho que pudesse acrescentar ao produto para que compensasse o salário recebido.

A jornada de trabalho era, para Taylor, simplesmente a fixação da distribuição do tempo e dos resultados que desembocam no que chamava de "tarefa-dia". A questão homens/hora, por sua vez, era encarada como a lógica normal da produtividade do trabalho comum, o que o trabalho normalmente poderia render, dilatando um pouco mais o montante executado da produção anterior: 1) aprimorando a velocidade do trabalho em virtude da contínua repetição do mesmo esforço; 2) sujeitando os trabalhadores rebeldes; 3 ) produzindo licenciamentos e 4) aumentando o exército de desempregados.

Os padrões de trabalho exigidos pela lógica taylorista situamse além do esforço físico e intelectual recuperável em uma noite de sono e através de uma alimentação normal. Sendo assim, esse tipo de esforço provoca, em geral, a somatização de doenças nos operários, stress e desinteresse pelo trabalho. Taylor conseguia vencer esses "empecilhos" por meios psicológicos como, por exemplo, fazer crer aos operários que o local de trabalho era o seu segundo lar, e exigindo, portanto, esforços cada vez maiores, dedicação, estima e zelo.

A idéia da extração de trabalho excedente, ou mais-valia, nasce justamente dessa forma de conceber o processo de trabalho. $O$ controle tecnológico é uma arma usada para, diretamente e em primeira mão, controlar o operário: é a partir do uso da máquina que o trabalhador torna-se seu próprio supervisor. A mais-valia, segundo Braverman, é entendida como o resultado de duas extrações simultâneas. A primeira, pela definição da potência do trabalho na própria máquina; a segunda, pela coerção do trabalho por métodos de diminuição salarial.

A submissão formal do trabalho ao capital baseia-se na maisvalia absoluta. A submissão real baseia-se na mais-valia relativa, acompanhada que é de uma revolução completa do modo de produção, da produtividade do trabalhador e das relações entre capitalistas e trabalhadores. A efetivação desta mais-valia só se dá pelo desenvolvimento das forças de produção social do trabalho, onde se encontra, como 
aliados, a aplicação da ciência e a mecanização do trabalho em grande escala.

Braverman monta a sua definição sobre o Taylorismo a partir de três principios fundamentais:

1- O cargo que a gerência ocupa, compreendendo, além de outras coisas, o conhecimento, regras, leis e fórmulas, que regulamentam as atividades simples e as complexas, faz com que caiba à administração tão somente descobrir métodos mais rápidos e econômicos que os trabalhadores possam executar seguindo todos os métodos implementados por ela.

2- Toda a concepção deve estar fora do chão de fábrica. $O$ planejamento, quer seja de natureza inventiva quer seja de natureza outra, deve ser pensado somente pela gerência. Aos trabalhadores só thes é permitido repetir movimentos definidos e não-pensados. Este postulado constitui-se na chave da organização científica: a separação entre concepção e execução. $O$ trabalho mental é separado do trabalho manual, deixando claro que a ciência do trabalho está sendo conduzida pela gerência.

3- A utilização do monopólio do conhecimento para controlar cada fase do processo de trabalho e seu modo de execução.

Encontra-se aqui a idéia do trabalho científico atrelado à gerência, como um instrumento poderoso que institucionaliza o divórcio da capacidade criadora dos operários de sua forma de intelectualizá-lo. $\dot{A}$ medida que os oficios são afastados da consciência dos trabalhadores, tornando as tarefas cada vez mais automatizadas, mais dificil se torna perceber a apropriação da Ciência pela gerência.

Várias facetas da produção foram retiradas do interior da oficina e transferidas para o escritório geral. As unidades de produção operam com "mão" vigiada e controladas por um "cérebro" distante.

Braverman explica como Taylor compreendeu bem a essência do princípio de Babage, que versa sobre como deve ser conduzida a capacidade do trabalhador. Cabe, portanto, ao trabalhador, somente uma parcela do conhecimento: a suficiente para pôr em prática as de- 
terminações prescritas pela gerência. Assim, nos diz Braverman: "Para o trabalhador cabc cumprir com seu dever, sem pensar e sem compreender raciocinios técnicos ou dados subjacentes". Fica claro que, por estc princípio, o controle da gerência das diversas esferas do processo de produção provoca o barateamento dos custos com pessoal, incorporados à nova lógica da organização: pois os próprios operários fariam as vezes de supervisores $\mathrm{e}$ coordenadores.

O controle deve ser compreendido como uma vigilância da produção, baseada $\mathrm{em}$ atividades previamente estudadas e calculadas, e que são inspecionadas e registradas durante e na fase conclusiva do processo produtivo.

Portanto, a fábrica taylorista implica em operações pormenorizadas e especializadas, cujo exercício não pode ser tarefa de um só opcrário. As repetições contínuas do mesmo ato também acabam por padronizar os niveis salariais setoriais e tornar o trabalho um "fator de produção" de fácil substituição.

O "adestramento" do trabalhador não se dá, necessariamente, pcla coerção: primeiro vem a manipulação, depois, quando necessário, a cocrção. A manipulação é produto de forças econômicas poderosas, politicas de cmprego e negociações que atuam como formas naturais de evolução do próprio sistema. ${ }^{4}$

A revolução técnico-científica aparece, nas últimas décadas do século XIX, como forma de condicionar a propriedade social e auxiliar a ciência. $O$ desenvolvimento da tecnologia, através de pesquisas cientificas, permite grandes transformações industriais. A incorporação da ciência à grande empresa capitalista provocou, não só o avanço da ciência teórica mas também da tecnologia, gerando a necessidade de expansão dos quadros de pesquisadores ligados à produção.

A característica do trabalho científico é, então, introduzir, com mais rapidez, os métodos produtivos tecnologicamente mais eficientes, permitindo que se melhore o capital-equipamento e se eleve a

${ }^{4}$ op.cit, p. 133 
potência do trabalho. Como contrapartida, a introdução de novas tecnologias faz do trabalho, cada vez mais, um trabalho alienado. menos cônscio das técnicas manipuladas. Sob a ótica dos salários, observa-se uma tendências de rebaixamento das remunerações das atividades atingidas pelo progresso tecnológico e, consequentemente, uma redução dos salários médios.

Em outras palavras, o que se quer aqui é discutir como a entrada em cena da tecnologia questiona os padrões de eficiência da produção e implica na redução dos salários médios. Se a força de trabalho especializa-se, ficam restringidas suas possibilidades de barganha no mercado de trabalho. Com isso, acresce a dependência dos trabalhadores em relação aos meios de produção e, consequentemente, a sua dependência dos proprietários do capital. Por esta razão, é alterada a relação de forças entre capital e trabalho, em favor do primeiro, o que implica, também sob este ângulo, numa tendência geral de diminuição dos salários.

Então, a aplicação da gerência científica, junto com a revolução técnico-científica, consiste numa das transformações (qualitativa $e$ quantitativa) fundamentais à estrutura e ao funcionamento da produção capitalista.

\section{UM BREVE COMENTARIO SOBRE O FORDISMO}

De fato, o grande êxito de Taylor estendeu-se muito além de sua vida, de seu trabalho prático. Muitos seguiram sua obra, conseguirido atingir objetivos semelhantes. Dentre estes, ressaltamos Henry Ford, criador de processos de aumentos de produtividade e de intensidade do trabalho também baseados em mecanismos denominados de "automação rígida".

O papel do fordismo é tão somente o de agilizar o processo de organização pensado por Taylor. Ao nível da organização é necessário que o trabalhador transforme-se numa força de trabalho geral e indiferenciada, adaptável a uma vasta gama de tarefas elementares. 
O fordismo pode ser considerado, ao mesmo tempo, como uma extensão c uma superação do taỵlorismo, na medida em que, ao incorporar a lógica tay.lorista em seus traços essenciais, desenvolve e aprofunda a capacidade de controle sobre o trabalho operário.Grosso modo. podemos apresentá-lo como uma inovação em relação ao taylorismo. scja pcla introdução da linha de montagem, seja pela introdução de uma nova forma de gestão da F.T.: uma nova política salarial.

$\mathrm{Na}$ introdução da linha de montagem, é a mecanização da circulação dos objetos e utensílios de trabalho que vai conduzir a articulação do trabalhador com a produção. Isso permite que o processo se torne mais compacto, chamando a atenção para e reduzindo, então, o absenteismo.

Outra forma de observar o impacto da linha de montagem sobrc o trabalho implica na fixação dos operários aos postos de trabalho cuja localização é rigorosamente determinada pela configuração do sistema de máquinas. Acrescente-se a isso a idéia, já semeada pelo taylorismo, da melhor alocação possível do tempo de trabalho (princípio de Babage): Ford introduz um rígido controle sobre o tempo de fabricação. Controla a jornada de trabalho e os movimentos dos trabalhadores. Isso tudo para reduzir sensivelmente a porosidade da jornada de trabalho.

Essa redução faz parte do sistema de "tempos alocados", onde o tempo gasto na execução de cada operação é determinado pela gerência, onde há um sistema de tempos impostos, e onde a cadência do trabalho é regulada de forma mecânica e externa ao corpo do trabalha. dor.

As transformações ocorridas ao nivel do desenvolvimento das forças produtivas, sob a ótica da valorização do capital, permitem fortes aumentos de produtividade, decorrentes tanto da extensão da jornada de trabalho, quando da coerção do trabalhador.

Sob esta ótica o debate é trazido para o campo do desenvolvimento da produção industrial, no qual a questão da automação é fundamental para a determinação da evolução da alienação do trabalhador face ao processo de trabalho. 
A automação rígida aliena o trabalhador. $\mathrm{O}$ indivíduo e a máquina pouco a pouco se identificam. Os movimentos do homem tornam-se tão mecânicos quanto os da máquina: "Sua capacidade inventiva se foi, nada mais lhe resta senão o continuo fazer repetitivo".

\section{$* \times *$}

Percebendo o ponto de tensão a que conduz o trabalhador, a estratégia do capital passa a ser a persuasão. Utiliza-se um discurso cooperativo e apaziguador das tensões sociais. Seu objetivo é, portanto, o de contraríestar uma crescente insatisfação produtiva via estímulos psicológicos de viés integrador: a negação do trabalho em cadeia, o enriquecimento das tarefas, a direção participativa, a formação permanente, como também a idéia de carreira, aparecem como tendências ideológicas deste novo discurso 5 .

A intolerância provocada pela crescente subordinação do trabalho, cada vez mais automatizado e controlado pela gerência científica, incentiva modificações nas condições de trabalho. Mesmo que estas sejam, como de fato o são, apenas na sua percepção: na forma de sentir e reagir do trabalhador a condições qualitativamente inalteradas de trabalho, $O$ que, por isso, não coloca em questão nem a propriedade do capital nem o grau de suas exigências de acumulação. As doenças "malditas" trazidas pelo desenvolvimento da tecnologia aparecem, com intensidade cada vez maior, nos flagelos causados pela automação: o absentismo $^{6}$, o "turnover"7 e a sabotagem são bons exemplos disso.

${ }^{5}$ Que o leitor reporte-se aos elogios do patronato ao modelo japonês de gestão ou, ainda, ao engrandecimento do processo de terceirização como método para a obtenção (via uma pseudo-integração empresarial do trabalhador) de uma produtividade e de uma qualidade acrescidas.

${ }^{6} \mathrm{O}$ absentismo, ou seja, o desperdício de trabalho, generalizase nos ramos industriais onde a resistência e a revolta exigem uma alternativa sistêmica. 
Estes surgem como indicadores do desperdício de tempo de trabalho, de redução da rentabilidade do capital e do aumento dos custos com serviços de inspeção e supervisão da mão-de-obra.

\section{NOTAS SOBRE A GESTÃO PSEUDO-PARTICIPATIVA}

As manifestações de resistência operária a métodos de dominação e automação que não se alteram qualitativamente desde a época de Taylor, abrem espaço para movimentos do tipo TOSP, TAF e Gestão Participativa.

A "desordem" gerada pelos movimentos de resistência, sobretudo em virtude do aumento da organização dos trabalhadores, desemboca na redução da taxa de lucro e da competitividade. Sob outro ângulo, estes movimentos de resistência impuseram o estigma da repressão $\mathrm{e}$ da violência à escola taylorista de administração de empresas.

Torna-se imperativo, então, para o capital, encontrar uma saída que permita a convivência dentro de relaçôes capitalistas de produção: "os operários não dão o máximo na produção porque estão em luta contra o patrão, por isso é necessário transformar essa luta num processo de integração econômica e ideológica".

Uma das formas encontradas para atingir esta integração está consubstanciada no plano "Scalon". As políticas contidas no plano Scalon pretendem amenizar os conflitos entre trabalhadores e patrões. O plano foi descrito por meio de quatro premissas:

a) garantir aumentos reais nos salários com base na relação produtividade total (real) e produtividade média.

'O "turnover", ou a mobilidade voluntária (?) dos trabalhadores, que se traduz na mudança intermitente de emprego em busca das condições salariais mais favoráveis, torna-se um grande tormento para a acumulação de capital, dado o aumento de custos provocado pela contratação de novos empregados. 
b) distribuir esses aumentos segundo os diversos níveis hierárquicos: os gerentes, chefes de produção, inspetores de linha e administradores teriam um adicional concedido pelo volume (oferta) de cada setor.

c) distribuir prêmios de produtividade a todos os empregados, independente das produtividades individuais: todos receberiam um valor compativel com a produtividade média.

d) permitir a participação dos empregados - via comitês de produção - na gestão das empresas.

Os resultados da chamada gestão participativa, pensamos, permitem apenas o adiamento dos conflitos de classe. E a fragilidade deste tipo de gestão está dada pelos seus condicionamentos, pelos fatores externo à firma que, por sua própria natureza, não podem ser controlados por simples políticas gerenciais. Apenas como exemplo, devemos observar que, no âmbito da repartição dos lucros, o resultado das políticas integracionais depende muito mais da participação e do tipo de inserção da firma no mercado do que de sua organização interna embora não se possa negar que a modernização da organização técnica da produção seja um elemento indispensável à resolução dos problemas integracionais apontados.

Da mesma forma, o mercado de trabalho tem pouca autonomia frente às questões de conjuntura. Assim, as opções das políticas participativas funcionam muito mais como um jogo de "cartas marcadas" do que como uma mudança qualitativa nas formas de gestão empresarial. Há quem diga (veremos abaixo) que a gestão participativa é apenas uma concessão do capital para que haja, por parte do coletivo dos trabalhadores, uma espécie de ilusão de integração, de não-marginalização.

Segundo André Gorz, por exemplo, "neste modelo ["participativo"] a pressão que o agente direto da produção sofre é suplantada pela liberdade de iniciativa, deixando de fato, nos cenários da gerência, o controle do trabalho e o modo de se efetivar o trabalho". E ainda, "desta forma, continua Gorz, a gerência não esconde a posição que ocupa, mas ao contrário, embora sutilmente, dê a impressão que 
está libertando, ao mesmo tempo que domina a iniciativa dos trabalhadores."

Através do modelo chamado "enriquecimento de cargos", que teria por fulalidade tornar o trabalho sempre original e desafiador, pretende-se, na realidade, alcançar uma melhoria na produtividade. A política básica deste modelo é a negação do parcelamento extremado das tarefas. Aqui os trabalhadores não seriam responsáveis por apenas uma parcela elementar do trabalho, mas por um conjunto de tarefas ${ }^{9}$. Através desta ampliação das responsabilidades, a gerência pretenderia uma maior integração e participação dos trabalhadores nas questões empresariais. No fundo, no entanto, o que está em jogo é a amenização dos conflitos classistas. As formas de participação foram desenvolvidas para aliviar conflitos oriundos da relação "capital $x$ trabalho", pelo menos ao nível da empresa. Esta participação do homem (trabalhador) na empresa, redimensiona o seu papel, pois consiste em fazer que os trabalhadores participem efetivamente das decisôes, tomem parte da direção. Assim, o conflito existente dentro da empresa, derivado em boa parte de fatores externos (como a situação econômico-social da região), mas também de fatores internos, tenderia a ser controlado por atos voluntarista da gerência empresarial.

Administrar o conflito, porém, não é tarefa fácil. Principalmente porque, à medida em que o capitalismo avança, é necessário dividir e hierarquizar sua força de trabalho. Deste processo resulta, basicamente, o surgimento de dois tipos de trabalho: o intelectual e $o$ manual, onde o primeiro domina claramente o segundo. Ora, os administradores pertencem a este primeiro tipo. São responsáveis pela própria sobrevivência da empresa, assim como garartem aos acionistas a

${ }^{8}$ op.cit. p. 110

${ }^{9} \mathrm{O}$ que implica, de fato, numa intensificação do trabalho. $\mathbb{E}$ isto sem que nenhuma qualificação the seja acrescida: não achamos que o trabalhador que antes colocava um prego numa esteira rolante fordis ta seja menos qualificado do que aquele que, hoje, vigia simultaneamente o funcionamento de dez máquinas. 
rentabilidade dos capitais aplicados. Pelas suas funções, os administradores tendem a se perpetuar no poder, ocorrendo então sua supervalorização funcional, quase sempre traduzida em altos salários. Os outros empregados, relegados a trabalhos manuais, perdem-se diante do gigantismo das operações realizadas dentro da empresa. Estão reduzidos apenas a peças ou máquinas que constituem o sistema, que o integram. Suas funções são tão repetitivas que há a perda de interesse, de iniciativa - ou mesmo de responsabilidade - em relação ao trabalho que executam. Todos estes fatos geram uma acomodação crescente, porque o trabalhador fica sem perspectivas e reproduz-se como um mero mecanismo.

Para se implantar uma verdadeira gestão participava, é necessária uma mudança de mentalidade. No entanto, como vimos, esta mentalidade também é determinada por fatores exteriores à empresa (concorrência, conjuntura nacional e internacional, fases do ciclo econômico, etc.). Logo, a gestão participativa não pode ser fruto de nenhum voluntarismo empresarial, e, o que é mais importante, não pode ser implantada sem substanciais alterações nos mecanismos econômi$\cos$ de apropriação e distribuição de riquezas.

\section{BIBLIOGRAFIA CITADA}

BRAVERMAN, H. - Trabalho e Capital Monopolista, São Paulo, Zahar, 1978

FLEURY M. H. e FICHER R.M. Processo e Relações do Trabalho no Brasil, Ed. Atlas, 1982.

GORZ, A. Divisão Social do Trabalho e Modo de Produção Capitalista. Lisboa, Escorpião, 1976. 